\title{
SIMULATION SUPPORT FOR PERFORMANCE ASSESSMENT OF BUILDING COMPONENTS
}

\author{
P A Strachan \\ ESRU, University of Strathclyde, Glasgow, Scotland
Contact: Paul Strachan, Energy Systems Research Unit, University of Strathclyde, 75 Montrose Street, Glasgow, Scotland, UK paul@esru.strath.ac.uk

\begin{abstract}
The determination of performance metrics for novel building components requires that the tests are conducted in the outdoor environment. It is usually difficult to do this when the components are located in a full-scale building because of the difficulty in controlling the experiments. Test cells allow the components to be tested in realistic, but controlled, conditions. High quality outdoor experiments and identification analysis methods can be used to determine key parameters that quantify performance. This is important for achieving standardised metrics that characterise the building component of interest, whether it is a passive solar component such as a ventilated window, or an active component such as a hybrid photovoltaic module.
\end{abstract}

However, such testing and analysis does not determine how the building component will perform when placed in a real building in a particular location and climate. For this, it is necessary to model the whole building with and without the building component of interest. A procedure has been developed, and applied within several major European projects, that consists of calibrating a simulation model with high quality data from the outdoor tests and then applying scaling and replication to one or more buildings and locations to determine performance in practice of building components.

This paper sets out the methodology that has been developed and applied in these European projects. A case study is included demonstrating its application to the performance evaluation of hybrid photovoltaic modules.

Keywords: Test Cells, Scaling, Modelling and simulation.

\section{Introduction}

One use of building component testing in the outdoor environment is to extract performance characteristics, e.g. by identification techniques [1], and compare them with similar components from other manufacturers or, after normalisation to standard conditions, to compare them with benchmarks. However, to assess how the component will perform when integrated into a full-scale building, this information is not enough. For example, it could be shown that a certain heat recovery is possible for a ventilated window component under fixed internal conditions inside an outdoor test cell. However, this would not take into account how this heat can be utilised in a particular building: the issue of utilisation will depend on building type, the operational regime, the external climate, other heat sources etc. The temporal matching of low-grade heat supply with building demands requires detailed knowledge of the building into which the component will be inserted. For example, it was shown that pre-heating of air from attached sunspaces [2] may have only limited applications. Another example is the operation of shading systems. Test cell experiments can be used to 
determine the performance of controllable glazing/shading elements, but knowledge of their application at the full scale is needed to study control options and the effect of high/low transmission states etc. Such interaction and utilisation issues can only be studied in full-scale demonstrations, which are very expensive, or by using whole building integrated simulation programs. Simulation then offers the bridge between the outdoor tests and full scale building performance prediction.

To enable performance assessments of building components at the full scale, a methodology was developed within the EC PASSYS project [3], and used in several later European projects involving outdoor testing of components (e.g. the IMAGE project on advanced glazings [4] and the PV-Hybrid-PAS project on heat recovery and electrical power from PV modules [5]). The focus was on integration - how the test components perform in a "real building" context when subject to realistic occupancy and use, over the full year.

The methodology has three elements:

- Calibration. This involves creating a simulation model of the test component and the test environment, undertaking simulations using the measured climatic data, and then comparing predicted performance with measured performance (temperatures, heat fluxes etc.). If successful, it gives confidence that the simulation program can correctly model the component characteristics when that component is subject to dynamically varying outdoor conditions. This process can be improved by using simulation for the design of experiments, to ensure that all the main influencing factors are measured.

- Scaling. This step requires the modelling of selected full-scale buildings for deployment of the building component under test. Simulations are undertaken of a base case of the building without the component, and then with the component included. Comparisons are made over a range of appropriate performance metrics such as energy consumption, thermal comfort and visual comfort. The technique allows a more realistic estimate of how the component will perform when it is fully integrated into a building, taking account of, for example, the utilisation of passive solar heating. In essence, it uses calibrated simulation models to extrapolate the test component measured performance, obtained from outdoor test cell experiments, to the full scale.

- Replication. This (optional) step involves repeating the simulations with different climate datasets and, perhaps, different local operational regimes to determine performance in different locations.

\section{Calibration versus Validation}

With regard to simulation, there are two ways in which experiments in outdoor test environments can be used: for empirical validation and for calibration. It is worth clarifying the distinction between the two as it has often led to confusion, although this paper is focussed primarily on calibration.

Table 1 shows the essentially different roles of the two techniques. 
$<$ Table 1: Comparison of Calibration and Validation $>$

\section{Calibration}

Calibration involves using experimental data to ensure that the model predictions align with the measured data over a realistic range of operating conditions. The calibrated model may then be used, with caution, to extrapolate to other contexts by means of scaling and replication procedures. Calibration is a critical element in the overall procedure - firstly, it should be comprehensive enough to ensure that all the main characteristics of the component are handled correctly (thermal, lighting, electrical etc.); but it must also be undertaken pragmatically to ensure that the performance of the component at the full scale remains the primary objective.

As has been noted by many workers, e.g. [6], calibrating a model can be problematic in that the user has to decide which of the inputs must be changed in order to reconcile measurements and predictions. There are two aspects to this problem. Firstly, the input parameter(s) that may be in error must be selected, or a deficiency in the simulation program must be isolated. Secondly, the modification(s) required to achieve a good fit must be calculated. The expertise of the user is a large factor in both cases.

This problem has been tackled in a number of ways: from manual, iterative, pragmatic intervention [7], [8], [9], [10]; through the production of a suite of informative graphical comparative displays [6] and the use of special tests and analysis procedures to isolate and compare individual energy flows [11], [12], [13], [14]; to a technique for automatically adjusting user selected input parameters to reduce the discrepancy between measured and predicted data [15], [16]. A recent paper [17] set out a comprehensive analytic framework for calibrating building energy systems. The method comprises a coarse-grid search to identify key parameters, followed by sensitivity analysis to identify a subset of the parameters having greatest influence on predictions, identifiability analysis to select parameters for tuning, optimization to determine the best fit of the identified parameters, and lastly uncertainty analysis to reduce the range of variation of these parameters.

These approaches are largely concerned with generic studies based on data from full-scale buildings. A different procedure was developed in the PASSYS project [3] and reported in [18]. This involves a multi-stage procedure using sensitivity analysis on selected parameters together with detailed analysis of those parameters identified as being the most influential in terms of energy consumption. In this case, the calibration procedure for component tests used detailed results obtained from the test cells to compare with the predicted data, in order to justify model modifications. To investigate which modifications could be made, several techniques were available, namely the use of additional sensors, sensitivity studies, residuals analysis and the use of lumped model parameters obtained from identification techniques.

In the assessment of novel building components in full scale implementation, a pragmatic approach to calibration was adopted (e.g. [4], [5]) which involved comparing measurements in outdoor test cells with model predictions, modifying or 'tuning' the model if necessary, and only resorting to detailed investigation and validation if time and resources permit. This is discussed in Section 3. 


\section{Validation}

Within the "calibration, scaling and replication" procedure outlined in the following section, it is assumed that the simulation program is capable of modelling all aspects of the building: only its ability to model the test component is investigated. Validation is aimed at ensuring that this assumption is true. Empirical validation, as one part of the overall procedure described in Table 1, is complex and time consuming, with a need for comprehensive high quality datasets. A whole-model empirical validation methodology was developed within the PASSYS project [19], [20], and there have been significant studies undertaken within IEA programmes (e.g. IEA Annex 21/ Task 12 [21]) and another is currently underway in IEA Task 34/ Annex 43 with a series of detailed well-defined experiments on outdoor test cells [22]. The main elements of empirical validation are:

- Use of modelling to help design the experiment - the accuracy required for the different measurements, the likely range of heat fluxes and temperatures etc.

- Use of laboratory measurements for important thermophysical and optical properties.

- Detailed documentation of the experiment.

- Production of high quality datasets in which the data have been checked for consistency and completeness.

- Undertaking a blind simulation comparing measurements with predictions so that the modeller is not influenced by the results of the experiment.

- Statistical analysis of differences between measurements and predictions, and study of additional sensor data, to determine the cause of any discrepancy - for example, a modelling bug or an incorrect modelling assumption.

- Refining the model if justified.

\section{Building Component Calibration, Scaling And Replication Procedure}

Essentially, calibration is the procedure by which a simulation model is checked, and if necessary tuned, to be "fit for purpose". In the context of building component model calibration, it involves using detailed component level measurements to confirm that the simulation model can adequately model the component. Calibration involves creating a simulation model of the test component and the test environment, undertaking simulations using the measured climatic data, and then comparing predicted performance with measured performance (temperatures, heat fluxes etc.). If successful, it gives confidence that the simulation program can correctly model the component characteristics.

To undertake a calibration, the following information is required:

- test set up (test cell type; infiltration data; test operation and conditions; dates of test etc.)

- test component (details of the component; thermophysical properties; dimensions, etc.)

- test data (climate - direct and diffuse solar radiation, wind speed and direction, ambient temperature; internal temperatures; heat fluxes; sample period and intervals etc.)

It should be ensured that a representative range of test conditions are covered in terms of the internal temperature range and external boundary conditions plus operational options.

Other important requirements are:

- Datasets should be fully documented, with notes of sensors, problems with instrumentation, and a description of any processing carried out on data. 
- Data gaps should be filled with realistic data (and noted in documentation). Any data spikes or missing data can cause difficulties with the modelling work.

An important step in the calibration is the "tuning" of the model. The advantage of using the outdoor test cells is that the experiments are well controlled, so the number of unknown parameters is significantly less than for whole buildings which have been the focus of most of the calibration studies referenced in the previous section. The procedure in this case is therefore relatively straightforward.

- Identify the modelling uncertainties when constructing the component model. These uncertainties are specific to the component under test, but experience from previous projects has been that internal convection coefficients are a major source of uncertainty for components with a ventilation function.

- Undertake sensitivity analyses over the likely parameter ranges for these uncertain parameters.

- Select appropriate values of these parameters to give acceptable agreement between the measurements and predictions over the range of test conditions. There is a risk of incorrect selection of parameters resulting in compensating errors, but because the models are relatively simple compared to those of full-scale buildings, there is much less over-parameterisation.

Scaling requires the selection of a one or more base case buildings, then undertaking a comparison of these base case buildings with and without the test component. Within previous EC projects (e.g. [4]), a performance assessment method was developed with the following main elements:

- Create a model of the base case building (as built, or as designed, without the new building component that is being studied).

- Establish representative boundary conditions (e.g. climate).

- Undertake integrated simulations using suitable simulation programs.

- Express multi-variate performance in terms of suitable design criteria.

- Identify potential configurations of the technology under study as a function of building type and location.

- Making use of the models tuned in the calibration study, create a series of models of the identified design cases. Care must be exercised to ensure that the component models are not used outside the range for which they have been calibrated.

- Compare the base case and design cases against the selected criteria.

- Consider further design cases to improve performance.

- Repeat the procedure for other climate zones to determine the sensitivity of a design to its location (this is termed replication).

\section{Case Study}

Several experiments and modelling studies were conducted on ventilated PV components within the PV-Hybrid-PAS project [5] and within further experiments on the Test Reference Environment (TRE) at the European Joint Research Centre (JRC) in Ispra, Italy. The TRE experiment described in this section was selected to demonstrate the ideas of calibration and scaling. The PV module under test had air flowing behind the module to cool the cells and act as a heat recovery system. The experiment was therefore a good example of a complex component, with a need to understand the thermal, airflow and electrical power aspects of the module performance.

The PV module under test was a $120 \mathrm{~cm}$ x $120 \mathrm{~cm}$ glass-glass polycrystalline (c-Si) silicon module composed of 121 cells arranged in 3 strings of 36 cells (plus an additional 13 cells). 
Two of these strings were connected in series to an inverter and the voltage and current measured at the maximum power point. Details of the modules as provided by JRC are given in Table 2.

$<$ Table 2: Construction and Electrical Details of the PV Component (STC are Standard Test Conditions of $1000 \mathrm{~W} / \mathrm{m}^{2}$ and $\left.25^{\circ} \mathrm{C}\right)>$

Previous experiments had shown that the largest differences between measured and predicted data occurred under conditions of high solar radiation and high flow rates. The data chosen for the analysis presented here were for 3 sunny days, 16-18 August 2002, when the ventilated air flow in the gap behind the module was measured as $78.2 \mathrm{l} / \mathrm{s}$. The module and a schematic cross section showing temperature sensor locations are shown in Figures 1 and 2.

$<$ Figure 1: PV Module mounted on Test Reference Environment $>$

$<$ Figure 2: Vertical cross-section schematic of experimental configuration $>$

The module was simulated with the ESP-r program [23], which is capable of modelling the integrated thermal, airflow and electrical power flow interactions. The model created comprised four stacked zones representing the air gap behind the PV module, to take into account stratification. A previous study had shown that at least 3 stacked zones were necessary to adequately predict temperature gradients behind the modules over a range of flow rates.

In earlier work undertaken to assist in the design of the outdoor test facility, a detailed sensitivity analysis was undertaken to determine the factors that most influence the electrical and thermal performance of PV modules. The parameters studied were grouped as follows:

- PV façade (front panel) thermophysical properties

- PV façade (rear panel) thermophysical properties

- Optical properties of the PV module

- Electrical properties of the PV module

- Climate

- Site conditions

The following were identified as the most significant parameters:

- PV cell encapsulating resin thickness and conductivity

- emissivity of surfaces in the air gap

- thermal capacity of the rear panel

- direct and diffuse solar radiation

- solar transmissivity (for semi-transparent modules) and absorptivity of the resin layer

- internal and external convection coefficients

- ground reflectivity

In the experiment described here, the details of the module and rear panel constructions were known in detail, and the vertical solar radiation in front of the modules was also measured. Figures 3, 4 and 5 indicate the agreement achieved (after tuning) between the measured and predicted data for the electrical power output from the 72 cells operated at maximum power point (MPP), for the temperature increase from bottom to top in the air gap, and the PV cell temperature. 
$<$ Figure 3: Comparison of predicted and measured power output from 72 cells at MPP $>$

$<$ Figure 4: Comparison of predicted and measured temperature increase in the air gap $>$

$<$ Figure 5: Comparison of predicted and measured PV cell temperature $>$

Regarding Figures 3, 4 and 5:

- The prediction for electrical power output for two strings of 72 cells is in good agreement with measurements. This is encouraging: it indicates that ESP-r's solar calculations of incident radiation on the south face (from the measured global and diffuse horizontal irradiation) and the PV cell algorithm give acceptable predictions.

- A number of sensitivity studies were carried out, altering the module optical properties, convective heat transfer coefficients in the air gap and emissivity in the air gap. Of these, uncertainty in optical properties and convective heat transfer coefficients were the most important. The agreement shown in Figures 3, 4 and 5 result from adjusting these parameters through a sensible range of values. This highlights the essential difference between calibration and validation: with these parameters providing an acceptable agreement, it was considered that the calibrated model was sufficiently accurate to allow it to be used in scaling and replication studies. The data were not of sufficient quality for validation.

- No optical information was available, and it is recommended that this data should be routinely measured for this type of component, as thermal performance is highly sensitive to solar absorptivity and reflectivity.

- Standard correlations were used for estimating the convection coefficients in the module air gap [24]. The best agreement was found using the assumption of laminar flow with a corresponding convective heat transfer coefficient of $2.16 \mathrm{~W} / \mathrm{m}^{2} \mathrm{~K}$. However, the modelling undertaken assumes uniform flow: in practice this is unlikely. More detailed measurements, together with CFD modelling, could be used to investigate this further [25]. However, it is re-iterated that the level of agreement reached is considered acceptable for scaling and replication studies.

- Although the dataset presented here is limited, with only one flow rate, other similar studies undertaken within the PV-Hybrid-PAS project [5] give some confidence in the results of the calibration, although there are still uncertainties regarding appropriate convective heat transfer coefficients.

Following calibration, a detailed scaling study was undertaken based on a model of the ELSA building in Ispra developed within the PV-Hybrid-PAS project [26]. The base case studied was the ELSA building, a large workshop situated in the EC Joint Research Centre at Ispra in the north of Italy, latitude $45^{\circ} 24^{\prime} \mathrm{N}$, as shown in Figure 6.

$<$ Figure 6: Focus of scaling example: the ELSA building, Ispra. $>$

$<$ Figure 7: Montage showing various components of the ELSA building model. $>$

The model includes the conditioned open-plan workshop floor level space (heated floor area is $1236 \mathrm{~m}^{2}$ ), the rest of the factory space and a detailed model of the PV facade using unventilated south-facing amorphous silicon PV modules (420 in total with an area of area $604 \mathrm{~m}^{2}$ ), as built. Some aspects of the model are shown in Figure 7. 
The intention of the following summary is to indicate how a calibrated model can be used to study component performance when integrated into a full scale building. The particular interest in the case of the ventilated PV modules was in how the heat recovered could be utilised, and so the objectives of this case study were to:

- investigate short term storage options for the heat recovered;

- investigate optimal combination of direct and short term storage options for the heat recovered;

- study summer stack ventilation cooling;

- contrast opaque crystalline (c-Si) and amorphous silicon (a-Si) PV modules.

The factory occupied zones were assumed to be convectively heated and cooled while the other spaces are only indirectly conditioned. The heating set-point was $20^{\circ} \mathrm{C}$ and the cooling set-point was $27^{\circ} \mathrm{C}$ when the factory was occupied (i.e. from 7:00 - 18:00 hours). The factory was assumed to be mechanically ventilated without a heat recovery system, with $8.7 \mathrm{~m}^{3} / \mathrm{s}$ or 7 $1 / \mathrm{s} . \mathrm{m}^{2}$ of fresh air supplied to the factory occupied zone. This relatively high ventilation rate was applied to be representative of a large workshop space where it was necessary to remove process contaminants as well as to investigate the maximum possible effect of the PV hybrid component.

The base case model contained a PV facade with no heat utilisation (i.e. a non-hybrid system). In order to quantify the possibility of a hybrid scheme, design changes to the base case were investigated.

- Design Case 1: Direct use of thermal heat recovery via a heat exchanger, investigating the potential for the direct use of thermal energy recovered from the facade in the workshop space via a heat exchanger.

- Design Case 2: Short-term storage, with a mechanical ventilation system connecting the PV facade air cavity and the workshop concrete floor mass.

- Design Case 3: Natural ventilation cooling of the factory occupied zone using the stack effect associated with the PV facade cavity.

- Design Case 4: Short-term storage with polycrystalline-Si modules such as modelled in the calibration study.

- Design Case 5: Conventional heat recovery to investigate how PV hybrid technologies compare with a conventional heat recovery system introduced to the base case model.

- Design Case 6: Direct use of thermal energy in the workshop space without a heat exchanger.

- Design Case 7: Combined direct and short-term storage.

- Design Case 8: Direct use plus heat recovery, with external air pre-heated in a heat exchanger and then drawn through the PV facade to further increase its temperature.

Full details of the models are reported in [26]. A few findings are presented here to indicate the benefits of this type of study. Compared to the base case:

- All Design Cases except Design Case 3 (natural ventilation cooling) and Design Case 6 (direct use without heat exchanger) result in a significant fan maximum capacity increase (between 70\% and 80\%).

- Application of c-Si PV modules significantly increases the maximum electric power generation capacity as well as the annual electric power generation (in the order of 3 times).

- In terms of total annual energy consumption, Design Case 8 (direct use plus heat recovery) will deliver a $25 \%$ reduction, and Design Cases 5 (conventional heat recovery), 6 (direct use without heat exchanger) and 7 (combined direct and shortterm storage) will each deliver about a $20 \%$ reduction. 
- The best performing option in terms of energy consumption, Design Case 8 (direct use plus heat recovery), could deliver total annual energy savings in the order of 68 $\mathrm{kWh} / \mathrm{m}^{2}$ normalised with respect to floor area and $141 \mathrm{kWh} / \mathrm{m}^{2}$ normalised with respect to PV facade area.

- Design Case 3 (natural ventilation cooling) will fail to deliver high ventilation rates, but may be a feasible solution if lower ventilation rates are acceptable. This scheme also slightly decreases the summer resultant temperatures.

- As a factory space, it may be possible to use the heat directly as process heat for some applications. The PV facade (Design Case 4) can generate up to a maximum of $30 \mathrm{~kW}$ of power, in the order of $50 \mathrm{MWh}$ in a year $\left(83 \mathrm{kWh} / \mathrm{m}^{2}\right.$ of façade area), and a maximum of $241 \mathrm{~kW}$ of heat (related to ambient temperature), in the order of 240 MWh (397 kWh $/ \mathrm{m}^{2}$ of façade area) in a year. There may be some industrial processes where this energy generation potential could make a useful contribution. The temperatures of the available heat will range from ambient under low solar conditions up to a maximum of $20^{\circ} \mathrm{C}$ above ambient.

It is straightforward to repeat simulations with other climate files to determine how the building component performs in other locations.

\section{Conclusions}

Simulation is an important part of the overall methodology for assessing the applicability of novel building components. It can be used to determine how the components will perform, against multi-variate criteria, when integrated into a full-scale building. This paper has reported on the calibration, scaling and replication procedures that have now been applied, in many EC projects and elsewhere, to understand the performance of new technologies. Examples are hybrid PV components, advanced glazings, add-on sunspaces, and ventilated facade components.

The first step is to use data from outdoor test cells to calibrate the computer model of the component. The advantage of using well-controlled outdoor experiments on novel building components is that most of the parameters required by the simulation model are known. Therefore the number of parameters that need to be considered in tuning to improve the match between measured and predicted data is reduced. Calibrated component models can then be used to study the potential impact of novel building components within full scale buildings.

\section{References}

[1] Jimenez M J and Madsen H, Models for Describing the Thermal Characteristics of Building Components, Building and Environment, this issue.

[2] Strachan P and Baker P, Comparison of Measured and Predicted Performance of a Conservatory, Proc. North Sun '92, Trondheim, Norway, pp345-350, June 1992.

[3] Wouters P and Vandaele L, The PASSYS Services: Summary Report, European Commission Publication No EUR 15113 EN, 1994.

[4] Clarke J A and Janak M, Assessing the Overall Performance of Advanced Glazing Systems, Solar Energy, Vol 63 (4), pp231-41, 1998.

[5] Vandaele L, Wouters P and Bloem H, Hybrid Photovoltaic Building Components: Overall Performance Assessment by Testing and Simulation, 14th European Photovoltaic Solar Energy Conference, Barcelona, pp1933-1936, 1997.

[6] Bronson D, Hinchey S B, Haberl J S, and O'Neal D L, A Procedure for Calibrating the DOE-2 Simulation Program to Non-Weather-Dependent Measured Loads, ASHRAE Transactions, Paper AN-92-1-5, pp. 636-652, 1992. 
[7] Carabott M, Building Simulation Reconciliation using Empirical Data, Proceedings of Building Simulation '89, Vancouver, Canada, 1989.

[8] Kaplan M B, McFerran J, Jansen J and Pratt R, Reconciliation of a DOE2.1C Model with Monitored End-Use Data for a Small Office Building, ASHRAE Transactions, Paper AN-9011-1, Vol. 96, Part 1, pp 981-993, 1990.

[9] Pedrini A, Westphal F S and Lamberts R, A Methodology for Building Modeling and Calibration in Warm Climates, Building and Environment, Vol 37 (8-9), pp 903-912, 2002.

[10] Tamburrini M, Palmer D and Macdonald I A, Calibrating Models for Simulation Use in Design Practices, Building Simulation '03, pp1273-1278, Eindhoven, Netherlands, Aug 2003.

[11] Subbarao K, Burch J D and Hancock C E, Building Energy Simulations for Design, Evaluation, Commissioning, Control and Diagnostics, Building Simulation '89, Vancouver, Canada, 1989.

[12] Balcomb J D, Burch J D and Subbarao K, Short-Term Energy Monitoring of Residences, ASHRAE Transactions 99(2), 1993.

[13] Soebarto V I, Calibration of Hourly Energy Simulations using Hourly Monitored Data and Monthly Utility Records for Two Case Study Buildings, Proceedings of Building Simulation '97, Prague, pp 411-419, Sept 1997.

[14] Liu S and Henze G P Calibration of Building Models for Supervisory Control of Commercial Buildings, Building Simulation '05, Montreal, Canada, pp641-648, Aug 2005.

[15] Carroll W L, Birdsall B E, Hitchcock R J and Kammerud R C, RESEM: An Evaluation Tool for Energy Retrofits in Institutional Buildings, Proceedings of Building Simulation '89, Vancouver, Canada, 1989.

[16] Carroll W L and Hitchcock R J, Tuning Simulated Building Descriptions to Match Actual Utility Data: Methods and Implementation, ASHRAE Transactions 99(2), 1993.

[17] Sun J and Reddy T A, Calibration of Building Energy Simulation Programs using the Analytic Optimization Approach (RP-1051), HVAC\&R Research, Vol 12 (1), pp 177-196, 2006.

[18] Clarke J A, Pernot C and Strachan P, An Approach to the Calibration of Building Energy Simulation Models, ASHRAE Transactions, Vol 99 (2), pp917-927, 1993.

[19] Jensen S O (Ed), The PASSYS Project. Subgroup Model Validation and Development Final Report, Parts I and II, 1986-1992 Commission of the European Communities, DGXII, 1993.

[20] Strachan P, Model Validation using the PASSYS Test Cells, Building and Environment, Vol 28 (2), pp 153-165, 1993.

[21] Lomas K J, Eppel H, Martin C and Bloomfield D, Empirical Validation of Thermal Building Simulation Programs using Test Room Data, IEA Annex 21/Task 12 Co-operative Project, Final Report, Vols 1,2 and 3, 1994.

[22] Manz H, Loutzenhiser P, Frank T, Strachan P, Bundi R and Maxwell G, Series of Experiments for Empirical Validation of Solar Gain Modeling in Building Energy Simulation Codes - Experimental Setup, Test Cell Characterization, Specifications and Uncertainty Analysis, in Press, Building and Environment, 2006.

[23] ESRU, ESP-r program, http://www.esru.strath.ac.uk, 2006.

[24] Incropera F P and DeWitt D P, Fundamentals of Heat and Mass Transfer, John Wiley and Sons, New York, 1996.

[25] Moshfegh B and Sandberg M, Flow and Heat transfer in the Air Gap Behind Photovoltaic Panels, Renewable and Sustainable Energy Reviews, Vol 2, Issue 3, pp287-301, 1998.

[26] Clarke J A, Hand J, Janak M, Johnstone C M and Strachan P A, PV-Hybrid-PAS Simulation Case Study: ELSA building, Ispra, Italy, PV-Hybrid-PAS Final Report, 1998. 
Table 1: Comparison of Calibration and Validation

\begin{tabular}{|l|l|l|}
\hline Objective & $\begin{array}{l}\text { Calibration, scaling and replication } \\
\text { Energy and environmental performance } \\
\text { assessment of new or existing } \\
\text { technologies in buildings }\end{array}$ & $\begin{array}{l}\text { Establishing confidence in } \\
\text { predictions of simulation programs }\end{array}$ \\
\hline Emphasis & $\begin{array}{l}\text { Quantitative assessment of building } \\
\text { performance }\end{array}$ & $\begin{array}{l}\text { Quantitative assessment of program } \\
\text { performance }\end{array}$ \\
\hline Applications & $\begin{array}{l}\text { Performance of typical buildings over a a } \\
\text { range of climates for overall assessment } \\
\text { Specific performance of design } \\
\text { exemplars }\end{array}$ & $\begin{array}{l}\text { Accreditation } \\
\text { Program development }\end{array}$ \\
\hline Elements & $\begin{array}{l}\text { Model development } \\
\text { Calibration } \\
\text { Component Performance } \\
\text { Scaling } \\
\text { Optimisation and Replication }\end{array}$ & $\begin{array}{l}\text { Theory Review } \\
\text { Source code checking } \\
\text { Inter-program comparisons } \\
\text { Analytical validation } \\
\text { Empirical validation (process level, } \\
\text { component level, whole-model level) }\end{array}$ \\
\hline
\end{tabular}

Table 2: Construction and Electrical Details of the PV Component (STC are Standard Test Conditions of $1000 \mathrm{~W} / \mathrm{m}^{2}$ and $25^{\circ} \mathrm{C}$ )

\begin{tabular}{|l|l|}
\hline Module Area & $120 \mathrm{~cm}$ x $120 \mathrm{~cm}$ \\
\hline Construction & $\begin{array}{l}\text { Glass }(4 \mathrm{~mm}), \text { PV cells in EVA (2mm), } \\
\text { Glass }(4 \mathrm{~mm})\end{array}$ \\
\hline Open circuit voltage of 36 cell string & 16.4 Volts at STC \\
\hline Short circuit current of 36 cell string & 2.24 Amps at STC \\
\hline $\begin{array}{l}\text { Voltage at maximum power point of } \\
36 \text { cell string }\end{array}$ & 21.3 Volts at STC \\
\hline $\begin{array}{l}\text { Current at maximum power point of } \\
36 \text { cell string }\end{array}$ & 2.58 Amps at STC \\
\hline Cell efficiency at STC & $10.00 \%$ \\
\hline
\end{tabular}




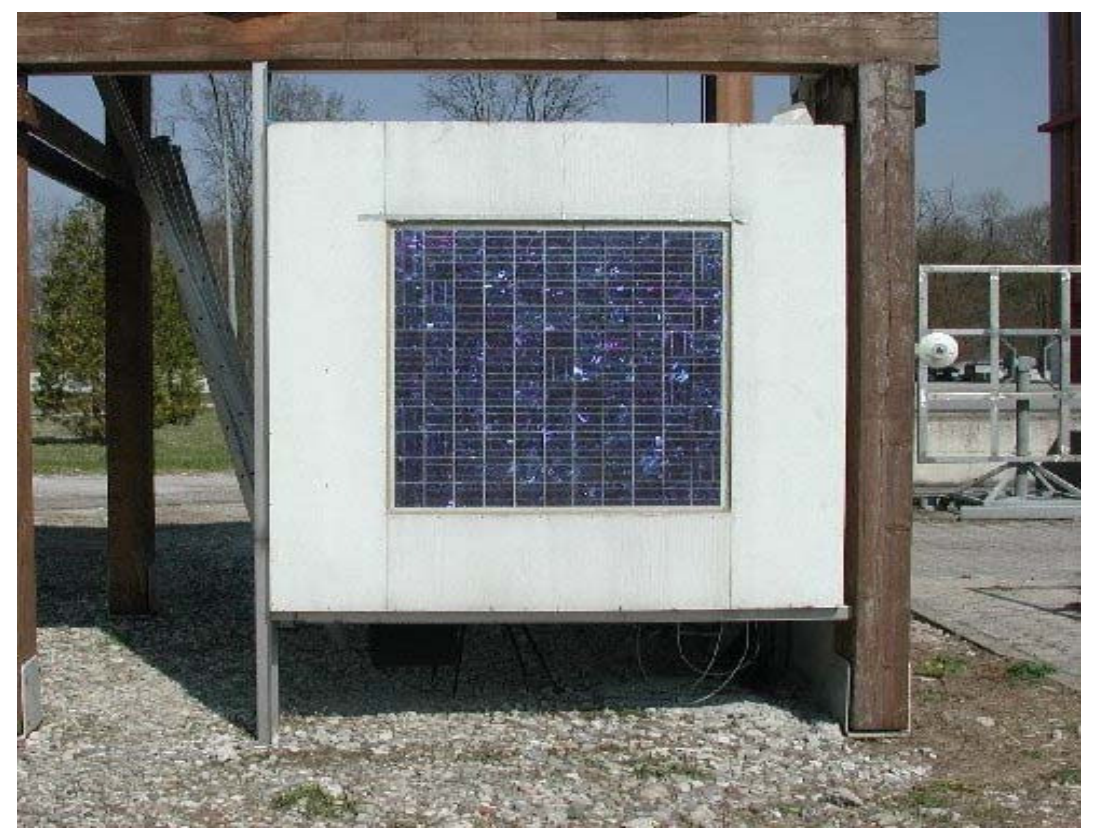

Figure 1: PV Module mounted on Test Reference Environment 


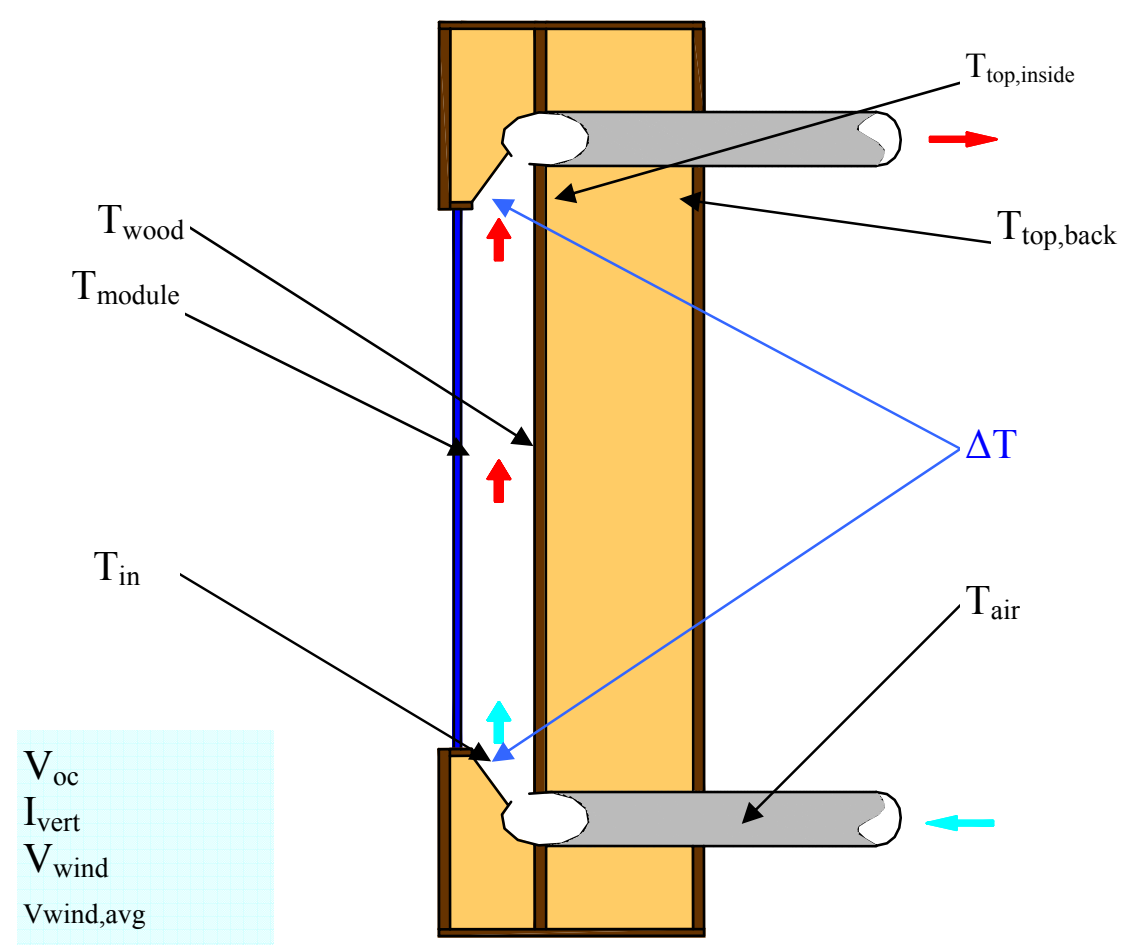

Figure 2: Vertical cross-section schematic of experimental configuration 


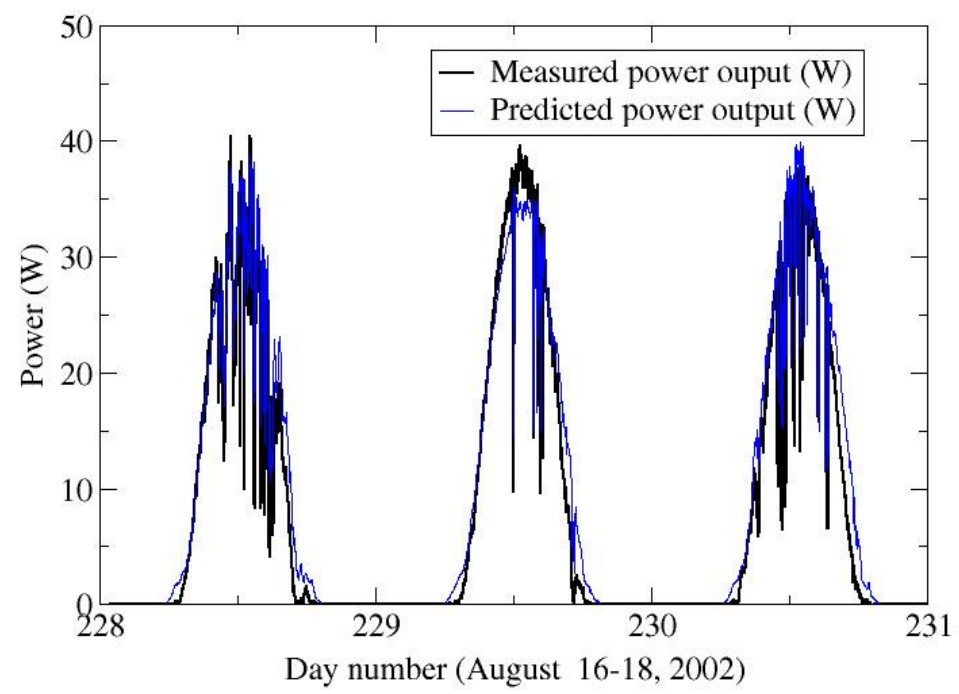

Figure 3: Comparison of predicted and measured power output from 72 cells at MPP

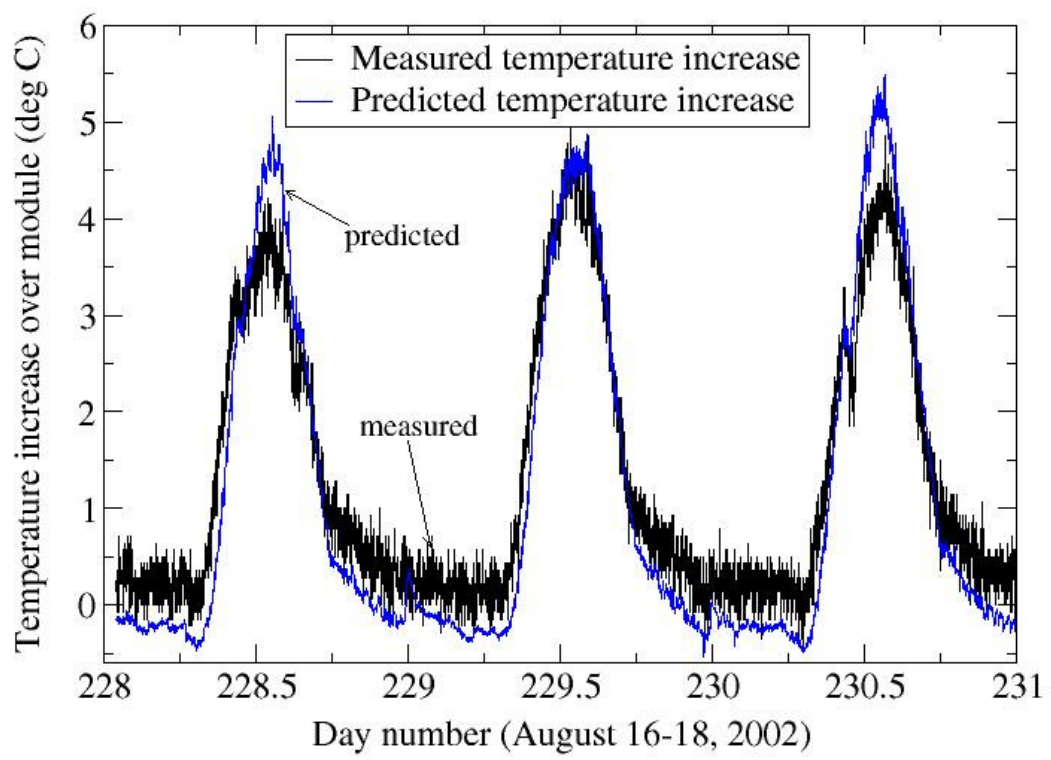

Figure 4: Comparison of predicted and measured temperature increase in the air gap 


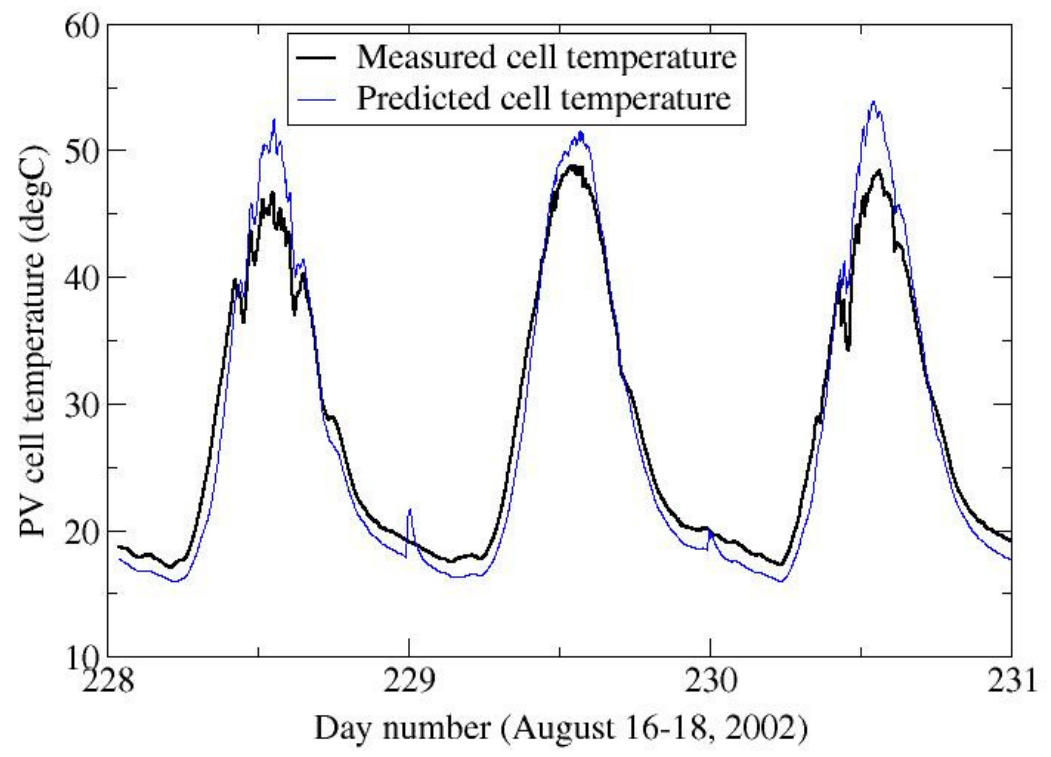

Figure 5: Comparison of predicted and measured PV cell temperature 


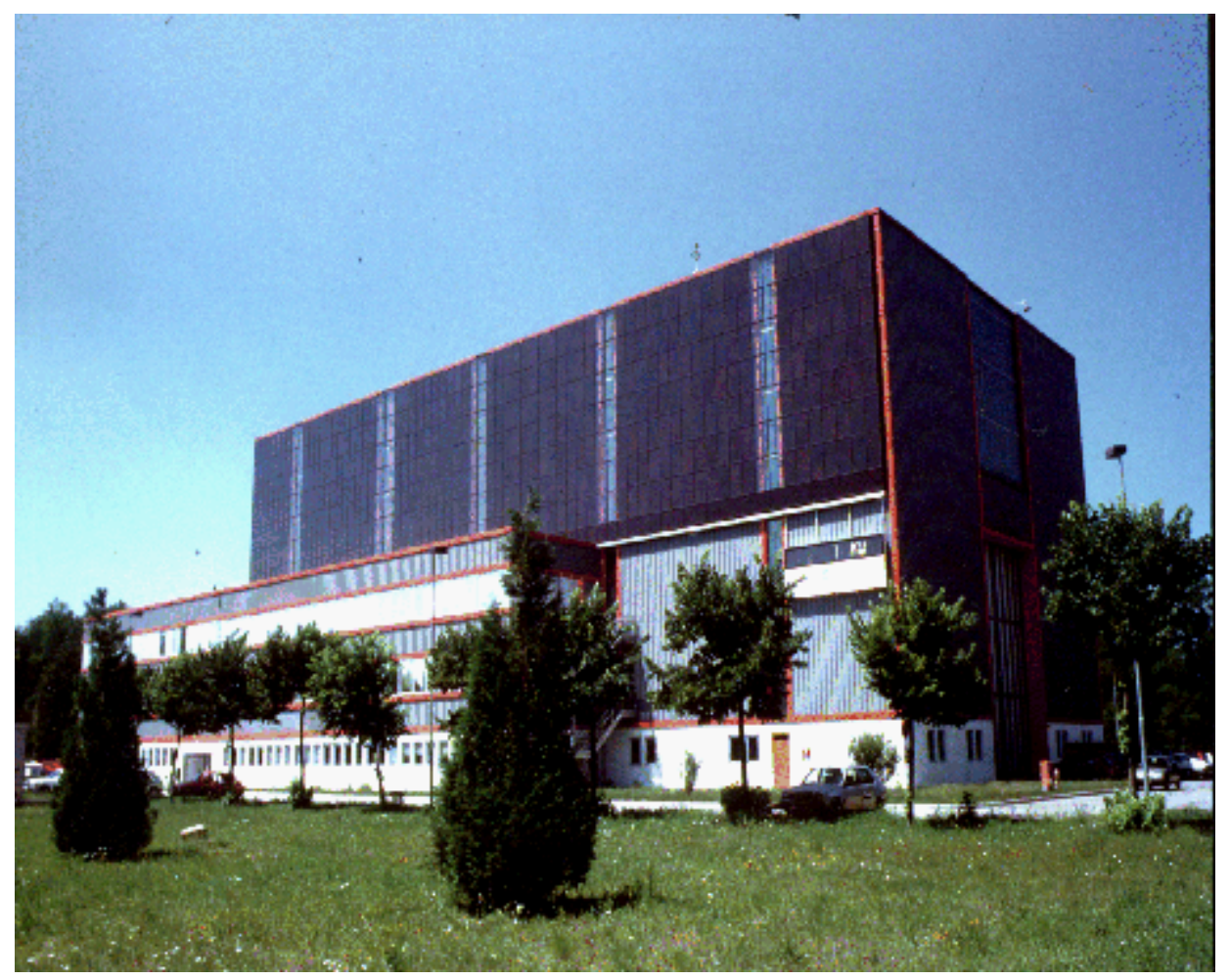

Figure 6: Focus of scaling example: the ELSA building, Ispra 


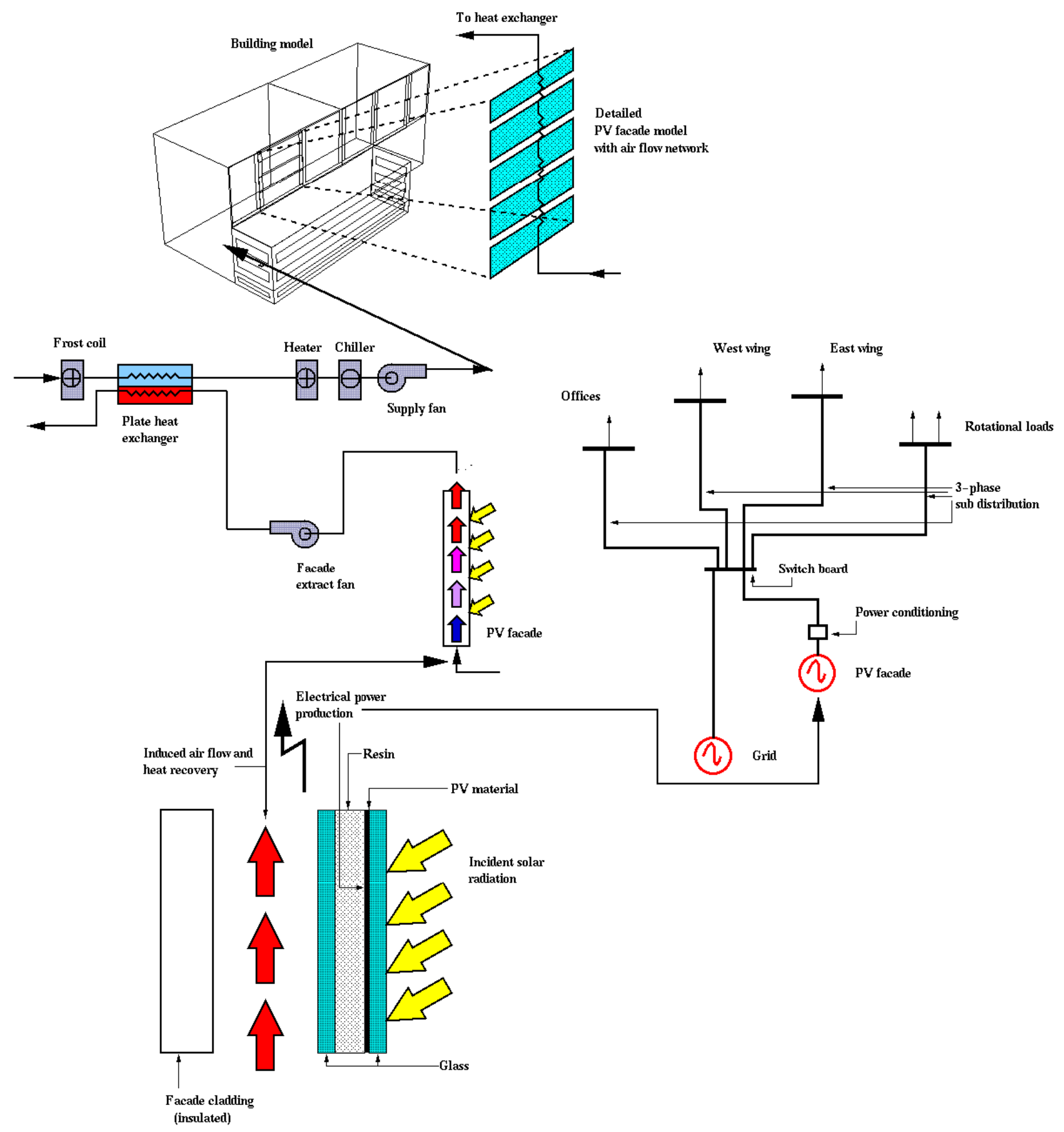

Figure 7: Montage showing various components of the ELSA building model. 